\section{Kidney \\ Blood Pressure Research}

\title{
Effect of Irbesartan on Chemerin in the Renal Tissues of Diabetic Rats
}

\author{
Qiu-Xia Yu Hong Zhang Wen-Hui Xu Fei Hao Su-Lai Liu Meng-Meng Bai \\ Jia-Wei Mu Hui-Juan Zhang
}

Department of Endocrinology, First Affiliated Hospital of Harbin Medical University, 23 Youzheng

Street, Nangang District, Harbin 150001, China

\section{Key Words}

Chemerin • Diabetic nephropathy $\cdot$ Renin-angiotensin system $\bullet$ Irbesartan

\begin{abstract}
Background/Aims: Chemerin was introduced as a novel adipokine that plays a crucial role in insulin signaling and diabetic nephropathy. Serum chemerin levels are significantly elevated in type 2 diabetes patients with macroalbuminuria. However, the underlying mechanisms remain unclear. We conducted a preliminary investigation of the effects of the reninangiotensin system (RAS) on chemerin expression in streptozotocin-induced diabetic rats. Methods: Streptozotocin-induced diabetic rats were randomized into control, diabetic, and irbesartan-treated groups. Real-time polymerase chain reaction was used to detect mRNA expression of chemerin, angiotensin II type 1a receptor (AT1a), angiotensin II type $1 \mathrm{~b}$ receptor (AT1b) and angiotensin II type 2 receptor (AT2). Immunohistochemical staining was used to detect chemerin in renal tissues. Results: Expression levels of chemerin in renal tissues were significantly elevated in the diabetic group compared to the control group. In the irbesartantreated group, chemerin expression levels and RAS-related protein levels (i.e. AT1a and AT1b) were markedly decreased compared to the diabetic group. Irbesartan treatment reduced chemerin overexpression and RAS-related protein levels in diabetic rats (i.e. AT1a and AT1b). Conclusion: Irbesartan may inhibit intrarenal RAS in diabetic rats, which may affect the expression of chemerin in the kidneys; however, the precise underlying mechanism remains to be determined.
\end{abstract}

\section{Introduction}

Adipose tissue is not only an energy storage depot, but also an active endocrine organ that produces and releases numerous metabolically active peptide hormones, adipokines, chemokines and cytokines. Chemerin, a recently discovered adipocytokine, has been shown to regulate adipocyte differentiation, modulate the expression of adipocyte genes, and play 


\section{Kidney \\ Blood Pressure Research}

key pathological roles in insulin resistance (IR), glucose metabolism and obesity [1]. It also functions as a proinflammatory adipocytokine that induces the cellular expression of inflammatory cytokines [2, 3], and is significantly associated with high sensitivity C-reactive protein, interleukin-6, tumor necrosis factor- $\alpha$, and white blood cell count [4-6]. Patients with chronic kidney disease and type 2 diabetes mellitus (T2DM) have elevated blood levels of chemerin $[7,8]$. These findings suggest a potential role for chemerin in the pathogenesis of nephropathy.

Diabetic nephropathy (DN) is the largest single cause of end-stage renal disease, representing a medical catastrophe worldwide. The pathological changes, such as expansion of mesangial cells, accumulation of extracellular matrix proteins, thickening of glomerular and tubular basement membranes, tubulointerstitial fibrosis, glomerulosclerosis, and renal endothelial dysfunction, are closely involved in the pathogenesis of DN and its microvascular complications [9].

The renal renin-angiotensin system (RAS) plays a pivotal role in the regulation of kidney function and participates in the progression of DN. Angiotensin II (Ang II), a major effecter molecule produced by the RAS, is critical for the development of DN [10-13]. Its actions are mediated through the Ang II receptors, type 1 receptors a and b (AT1a and AT1b, respectively) and type 2 receptor (AT2). AT1 has been associated with vasoconstriction, sodium re-absorption and growth promotion, while AT2 has been associated with opposing actions. Blocking Ang II with AT1 antagonists is one of the best options for treating renal diseases [14]. Irbesartan is a noncompetitive AT1 antagonist (ARB) that has been used successfully for treating DN [15]. However, the effect of RAS blockers on plasma chemerin levels has not been demonstrated definitively. Thus, the aim of this preliminary study was to determine the effects of RAS on the expression of chemerin in the renal tissues of streptozotocin-induced diabetic rats.

\section{Materials and Methods}

\section{Animals}

Thirty healthy Sprague Dawley rats (200-250g) were utilized in this study. The animal protocol was approved by the ethics committee of the First Affiliated Hospital of Harbin Medical University for Animal Studies, and animals were handled according to the "Principles of laboratory animal care." Rats were randomly divided into three groups: a normal control group (receiving only a normal-calorie diet), a diabetic group, and a diabetic + irbesartan treatment group. Rats in the diabetic and diabetic + irbesartan groups were fed the same diet containing 59\% basic mouse feed, 20\% sugar, $18 \%$ lard, and 3\% egg yolk, as previously described [16]. After 6 weeks, low doses of streptozotocin (STZ) (35mg/kg, i.p., Sigma, St. Louis, MO, USA) prepared in $0.1 \mathrm{~N}$ citrate buffer, $\mathrm{pH} 4.5$ were given to rats in the diabetic and diabetic + irbesartan groups. Age-matched control group rats were injected with normal saline (NS) only. Rats with fasting blood glucose levels $>16.7 \mathrm{mmol} / \mathrm{L}$ were considered to be have T2DM. The diabetic rats in the irbesartan treatment group were given irbesartan $(40 \mathrm{mg} / \mathrm{kg})$ by intragastric administration, while conscious, once a day for 8 weeks. The control and DM groups received vehicle alone.

\section{Biochemical Analysis}

After 8 weeks of treatment, prior to terminating the experiment, the rats were placed in metabolic cages to collect 24-hour urine samples from which urinary albumin levels were measured. Blood samples were collected from the tail veins after a 16-h fast. Blood glucose (BG), cholesterol (CHOL), triglycerides (TG), blood urea nitrogen (BUN) and serum creatinine (Scr) were measured in a certified laboratory.

\section{Real-Time PCR}

Rat kidneys were harvested after perfusion and flushing with saline. Total RNA was isolated from a whole kidney homogenate using Trizol reagent (Invitrogen, Carlsbad, CA, USA) according to the manufacturer's protocol. A reverse transcription (RT) system kit (Applied Biosystems, USA) was then used 


\section{Kidney \\ Blood Pressure Research}

to reverse transcribe $1 \mu \mathrm{g}$ of total RNA. Relative levels of mRNA for chemerin, AT1a, AT1b and AT2 were determined by realtime PCR with the ABI Prism 7000 sequence detection system (Applied Biosystems, Foster City, CA, USA). Primers designed and used for chemerin AT1a, AT1b, and AT2 are shown in Table 1. To control for variations in the amount of DNA available for PCR in the different samples, the expression levels of target genes were normalized according to that of $\beta$-actin. The results were analyzed using the $\Delta$ Ct technique.

\section{Western blot analysis of renal chemerin expression}

Frozen renal tissues were homogenized on ice in a lysis buffer and, after sonication, the clear supernatants were used for Western blot analyses. Protein concentrations were measured, and $50 \mu \mathrm{g}$ of protein was added to the sample buffer. The mixtures were boiled for $5 \mathrm{~min}$ and loaded onto an $8 \%$ sodium dodecyl sulfate (SDS)-polyacrylamide gel. Following electrophoresis, the separated proteins were transferred onto nitrocellulose membranes (Amersham Biosciences, Little Chalfont, Buckinghamshire, UK) using a wet transfer method. The membranes were blocked with 5\% non-fat milk and 0.05\% Tween 20 in Tris-buffered saline (TTBS). After blocking, the membranes were incubated with anti-rat chemerin antibody (Santa Cruz Biotechnology, Santa Cruz, CA, USA; $1: 1000$ ) at $4^{\circ} \mathrm{C}$ overnight. The membranes were then washed with TBST and incubated with a 1:2000 dilution of the corresponding secondary antibody at room temperature for $1 \mathrm{~h}$ with agitation. Protein bands were detected with ECL Western blotting detection reagents.

\section{Immunohistochemical staining}

Formalin-fixed paraffin-embedded tissue samples were cut into 4 - $\mu \mathrm{m}$-thick serial sections and mounted on glass slides. The sections were dewaxed in xylene and re-hydrated stepwise in ethanol, followed by heatinduced antigen retrieval using $10 \mathrm{mmol} / \mathrm{L}$ citrate buffer (pH 6.0) in a steamer. Endogenous peroxidase activity was quenched by incubating the sections with $3 \%(\mathrm{v} / \mathrm{v})$ hydrogen peroxide at room temperature for $15 \mathrm{~min}$. Then, the primary antibody, monoclonal mouse anti-rat chemerin antibody (diluted 1:100; Santa Cruz Biotechnology), was added and then incubated overnight at $4{ }^{\circ} \mathrm{C}$. The corresponding secondary antibody was then added and incubated for 30 min with streptavidin-horseradish peroxidase conjugate. Finally, immunolabeled sections were visualized using 3,3'-diaminobenzidine (DAB), and then counterstained with hematoxylin, dehydrated, and mounted. The immunohistochemical staining of chemerin was quantified by Image-Pro Plus 6.0 software (Media Cybernetics, Inc) and the results were presented as integrated optical density (IOD).

For hematoxylin-eosin (HE) staining, formalin-fixed, paraffin-embedded, tissue samples were cut into $4-\mu \mathrm{m}$-thick serial sections and mounted on glass slides. The sections were dewaxed in xylene and rehydrated stepwise in ethanol. The tissues were then stained with hematoxylin and eosin.

For periodic acid-Schiff (PAS) staining, the tissue slides were incubated with periodic acid solution for $10 \mathrm{~min}$. They were then washed in deionized water, and incubated in Schiff reagent, 70\% ethanol, and reducing solutions for $1 \mathrm{~min}$. After the sections were washed with basic fuchsin in $70 \%$ ethanol for $1 \sim 1.5 \mathrm{~h}$, they were counterstained with hematoxylin for 3-5 min, dehydrated, cleared, and mounted with coverslips.

\section{Statistical analyses}

Statistical analyses were performed using SPSS version 17.0 software (Chicago, IL, USA). Data are expressed as means \pm SD. For three-group comparisons, data were analyzed by ANOVA. The Fisher least significant difference (LSD) test was then implemented for post-hoc analysis. If variances across the

\begin{tabular}{|c|c|c|}
\hline Genes & Primers & Sequence $\left(5^{\prime}-3^{\prime}\right)$ \\
\hline \multirow[t]{2}{*}{ Chemerin } & forward primer & AATGGGAGGAAGCGGAAATG \\
\hline & reverse primer & AGGGAAGAAGTAGATGCGGGAGT \\
\hline \multirow[t]{2}{*}{ AngIIAT1a } & forward primer & GGAAACAGCTTGGTGGTGAT \\
\hline & reverse primer & ACATAGGTGATTGCCGAAGG \\
\hline \multirow[t]{2}{*}{ AngIIAT1b } & forward primer & GGAAACAGCTTGGTGGTGAT \\
\hline & reverse primer & GCTGGCAGAAGCGATCTTAC \\
\hline \multirow[t]{2}{*}{ AngIIAT2 } & forward primer & CCCTGGCAAGCATCTTATGT \\
\hline & reverse primer & CCAGCAGACCACTGAGCATA \\
\hline \multirow[t]{2}{*}{$\beta$-actin } & forward primer & ACTCTGTGTGGATTGGTGGC \\
\hline & reverse primer & AGCTCAGTAACAGTCCGCCT \\
\hline
\end{tabular}




\section{Kidney \\ Blood Pressure Research}

Yu/Zhang/Xu/Hao/Liu/Bai/Mu/Zhang: Irbesartan Effects on Chemerin in Diabetic Rats

Table 2. Correlation between chemerin expression, post-treatment blood glucose and changes in blood glucose with parameters of renal function, RAS-related proteins and integrated optical density in all 26 rats of the three group

\begin{tabular}{|c|c|c|c|c|}
\hline & $\begin{array}{c}\text { Chemerin expression } \\
\text { (mRNA) }\end{array}$ & $\begin{array}{c}\text { Chemerin } \\
\text { expression (IOD) }\end{array}$ & $\begin{array}{c}\text { Post-treatment } \\
\text { BG } \\
\end{array}$ & $\begin{array}{c}\text { Post-treatment } \\
\text { change of BG }\end{array}$ \\
\hline Variables & $\rho(P$-value $)$ & $\rho$ (P-value $)$ & $\rho(P$-value $)$ & $\rho(P$-value $)$ \\
\hline $\begin{array}{l}\text { Blood urea nitrogen, } \\
\mathrm{mmol} / \mathrm{L}\end{array}$ & $0.765\left(<0.001^{*}\right)$ & $0.675\left(<0.001^{*}\right)$ & $0.740\left(<0.001^{*}\right)$ & $-0.372(0.061)$ \\
\hline $\begin{array}{l}\text { Serum creatinine, } \\
\mu \mathrm{mol} / \mathrm{L}\end{array}$ & $0.861\left(<0.001^{*}\right)$ & $0.791\left(<0.001^{*}\right)$ & $0.835\left(<0.001^{*}\right)$ & $-0.085(0.680)$ \\
\hline $\begin{array}{l}\text { Urinary albumin, } \\
\mathrm{mg} / 24 \mathrm{~h}\end{array}$ & $0.881\left(<0.001^{*}\right)$ & $0.783\left(<0.001^{*}\right)$ & $0.864\left(<0.001^{*}\right)$ & $-0.095(0.643)$ \\
\hline AT1a & $0.415\left(0.035^{*}\right)$ & $0.459\left(0.018^{*}\right)$ & $0.352(0.078)$ & $0.552\left(0.003^{*}\right)$ \\
\hline AT1b & $0.526\left(0.006^{*}\right)$ & $0.659(<0.001 *)$ & $0.521\left(0.006^{*}\right)$ & $0.313(0.120)$ \\
\hline AT2 & $0.749\left(<0.001^{*}\right)$ & $0.698\left(<0.001^{*}\right)$ & $0.749\left(<0.001^{*}\right)$ & $-0.323(0.107)$ \\
\hline
\end{tabular}

Abbreviation: BG: blood glucose; IOD: integrated optical density; Spearman's rank correlation was implemented. $* P<0.05$

groups were heterogeneous, Dunnett's T3 test was used instead. The alpha level was adjusted to 0.017 $(\fallingdotseq 0.05 / 3)$ when the post-hoc tests were carried out. Spearman's rank correlation was performed to examine the correlations between chemerin expression / blood glucose/IOD and other variables (Scr, BUN, urinary albumin, AT1a, AT1b, and AT2). Five levels of correlation are defined: very weak $(\rho<0.2)$, weak $(0.2 \leq$ $\rho<0.4)$, moderate $(0.4 \leq \rho<0.6)$, strong $(0.6 \leq \rho<0.8)$, and very strong $(\rho \geq 0.8)$. A $P$-value of less than 0.05 was established as being statistically significant.

\section{Results}

\section{General data analysis}

Table 2 shows the correlation between chemerin expression with parameters of renal function and RAS-related proteins in all 26 rats of the three groups. In addition, the association between post-treatment blood glucose levels and post-treatment changes in blood glucose levels with renal function parameters and RAS-linked proteins was determined (Table 2). Chemerin mRNA expression as well as protein expression (IOD) were related to all renal parameters assessed, including BUN, serum creatinine, and urinary albumin, as well as AT1a, AT1b, and AT2 expression (all $P \leq 0.035$ ). Similarly, post-treatment blood glucose levels were significantly correlated with all of these indices (all $P \leq 0.006$ ) with the exception of AT1a levels, which was associated with post-treatment changes in blood glucose levels (Table 2; $P=0.003$ ). Furthermore, post-treatment blood glucose was highly correlated with chemerin expression $(\rho=0.844, P<0.001)$.

The biochemical and renal parameters of the three groups are summarized in Table 3. We found significant differences in BG, CHOL, TG, Scr, BUN, urinary albumin levels, and chemerin protein expression between the diabetic and the control groups $(P<0.05)$. After 8 weeks of irbesartan treatment, BG, Scr, urinary albumin levels and chemerin protein expressionwere significantly decreased $(P<0.05)$, while no significant differences were found in the other parameters $(P>0.05)$.

\section{Immunohistochemical and Western blot analyses of chemerin expression}

Fig. 1 shows representative photomicrographs of immunohistochemical analysis of chemerin in the renal tissues of all three groups. The expression of chemerin was significantly elevated in the diabetic rats compared to the control group, and irbesartan treatment 


\section{Kidney Blood Pressure Research}

Table 3. Biometric parameters of rats by group

\begin{tabular}{lccc}
\hline Parameters & $\begin{array}{c}\text { Control } \\
\text { group } \\
(\mathrm{n}=10)\end{array}$ & $\begin{array}{c}\text { Diabetic } \\
\text { group } \\
(\mathrm{n}=8)\end{array}$ & $\begin{array}{c}\text { Diabetic + Irbesartan } \\
\text { treated group } \\
(\mathrm{n}=8)\end{array}$ \\
\hline Body weight $(\mathrm{g})$ & $217.8 \pm 12.9$ & $247.3 \pm 46.6 \mathrm{a}$ & $254.4 \pm 14.1 \mathrm{a}$ \\
BG $(\mathrm{mmol} / \mathrm{L})$ & $4.7 \pm 0.4$ & $18.9 \pm 3.4^{\mathrm{a}}$ & $14.1 \pm 2.1 \mathrm{ab}$ \\
CHOL $(\mathrm{mmol} / \mathrm{L})$ & $1.7 \pm 0.3$ & $3.9 \pm 0.7 \mathrm{a}$ & $3.4 \pm 0.2^{\mathrm{a}}$ \\
TG $(\mathrm{mmol} / \mathrm{L})$ & $0.8 \pm 0.2$ & $1.8 \pm 0.2^{\mathrm{a}}$ & $1.8 \pm 0.4 \mathrm{a}$ \\
FINS $(\mathrm{mU} / \mathrm{L})$ & $12.2 \pm 2.0$ & $30.2 \pm 2.1 \mathrm{a}$ & $28.6 \pm 2.4 \mathrm{a}$ \\
Scr $(\mu \mathrm{mol} / \mathrm{L})$ & $30.8 \pm 1.7$ & $51.6 \pm 2.2 \mathrm{a}$ & $35.4 \pm 1.0 \mathrm{ab}$ \\
BUN $(\mathrm{mmol} / \mathrm{L})$ & $5.9 \pm 0.6$ & $13.4 \pm 1.3 \mathrm{a}$ & $12.4 \pm 0.9 \mathrm{a}$ \\
Urinary albumin $(\mathrm{mg} / 24 \mathrm{~h})$ & $3.3 \pm 0.6$ & $37.2 \pm 3.4 \mathrm{a}$ & $16.7 \pm 3.3 \mathrm{ab}$ \\
Chemerin expression $(\mathrm{IOD})$ & $7.4 \pm 1.3$ & $12.8 \pm 1.7 \mathrm{a}$ & $9.5 \pm 1.3 \mathrm{ab}$ \\
\hline
\end{tabular}

Data are expressed as mean \pm SD. BG, blood glucose; CHOL, cholesterol; TG, triglycerides; FINS, free insulin; Scr, serum creatinine; BUN, blood urea nitrogen; IOD: integrated optical density. a $P<0.05$ versus control group; ${ }^{\circ} P<0.05$ versus diabetic group
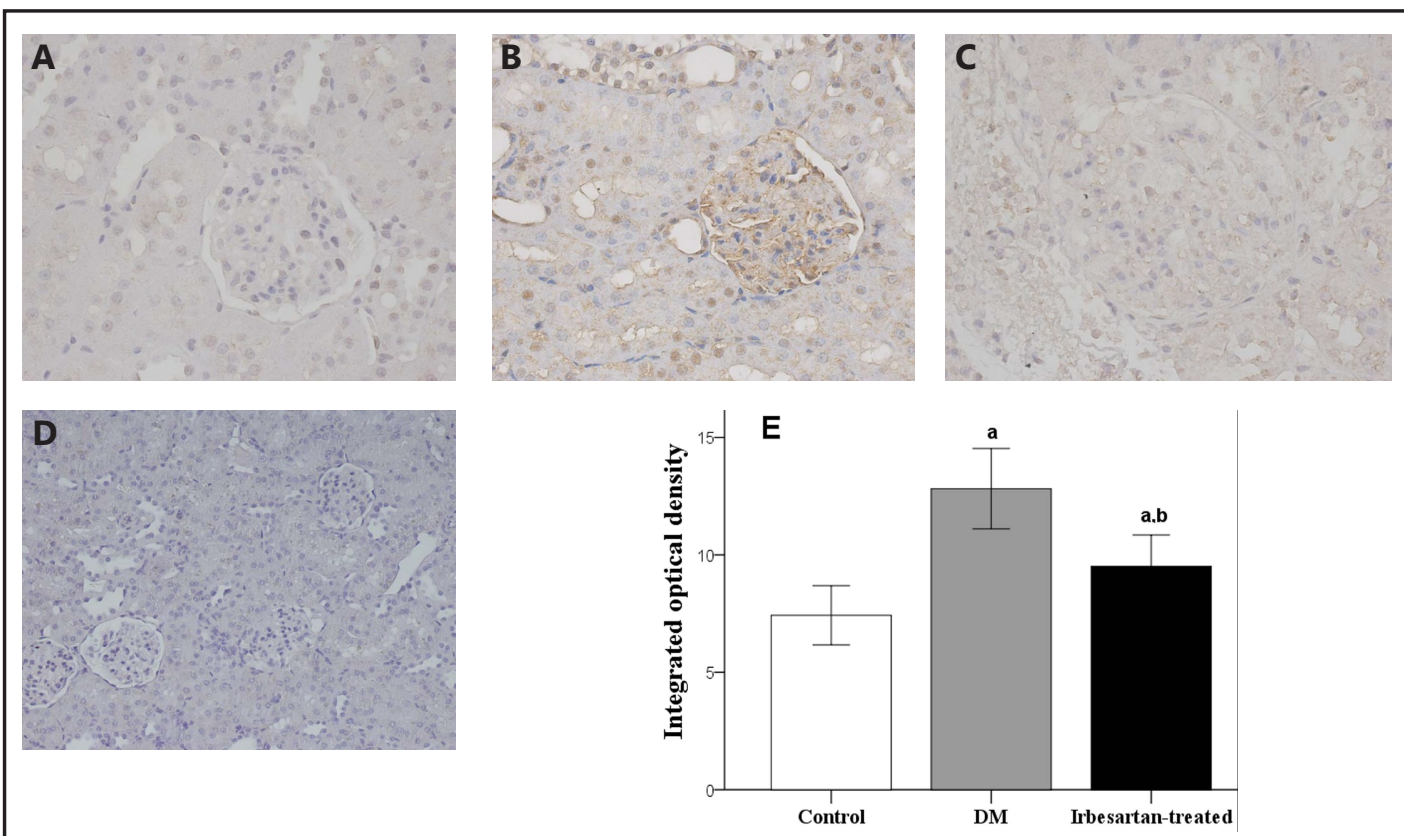

Fig. 1. Effects of irbesartan on chemerin expression in the kidneys of diabetic rats. Representative immunohistochemical staining for chemerin in the kidneys of rats from the A. control group, B. diabetic group, and C. irbesartan-treated group. D. is a negative control. E. is the quantitative result presented as integrated optical density.

Fig. 2. Western blot analysis of chemerin expression in the kidneys of the three groups.

significantly decreased its expression in diabetic rats. Fig. 2 shows a similar expression profile of chemerin by Western blot analysis, in which the expression of chemerin was elevated in diabetic rats and

chemerin

$\beta$-actin

Control Diabetic $\begin{gathered}\text { Irbesartan- } \\ \text { treatment }\end{gathered}$ decreased with irbesartan. 


\section{Kidney \\ Blood Pressure \\ Research}

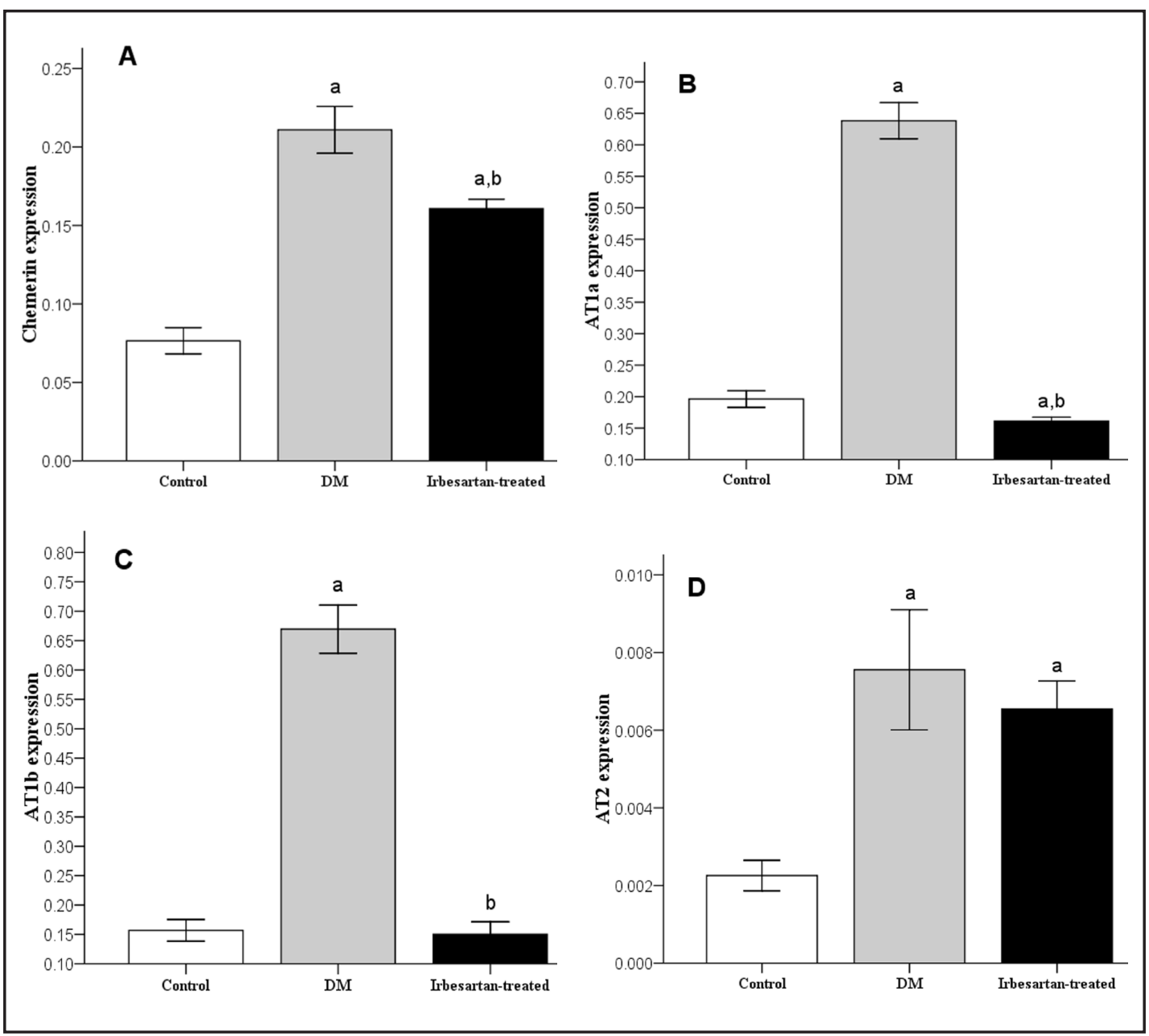

Fig. 3. Effects of irbesartan on chemerin, AT1a, AT1b and AT2 mRNA expression. A, chemerin, B. AT1a, C. AT1b, D. AT2 mRNA was quantified by real-time PCR in the renal tissue of the three groups. Data are presented as fold change of transcripts for the target gene in the indicated groups normalized to $\beta$-actin. Data are presented as mean \pm standard deviation $(n=10$ for the control group, $n=8$ for the diabetic and irbesartan-treated groups). One-way analysis of variance (ANOVA) followed by Fisher's least significant difference (LSD) test or Dunnett's T3 test for post-hoc tests was performed. ${ }^{a} P<0.05$, significantly different versus the control group. ${ }^{b} P<0.05$, significantly different versus the diabetic group.

Chemerin and AT1a, AT1 $b$ and AT2 $m R N A$ levels in the three groups

As shown in Fig. 3A, real-time PCR analysis demonstrated that the expression of chemerin mRNA was significantly elevated in the diabetic rats compared to the control rats. After 8 weeks of irbesartan treatment, the expression of chemerin mRNA was markedly decreased in the kidneys of the irbesartan-treated rats compared to those of rats in the diabetic group. Evaluating the levels of AT1a and AT1b mRNA between the three groups showed that AT1a and AT1b were significantly increased in the diabetic group and were significantly decreased in the diabetic + irbesartan group (Fig. 3B and 3C). In addition, we observed significant differences in AT2 levels between rats in the diabetic and control groups; however, no significant differences in the levels of AT2 were observed between the diabetic + irbesartan group and the untreated diabetic group (Fig. 3D). 


\section{Kidney \\ Blood Pressure \\ Research}

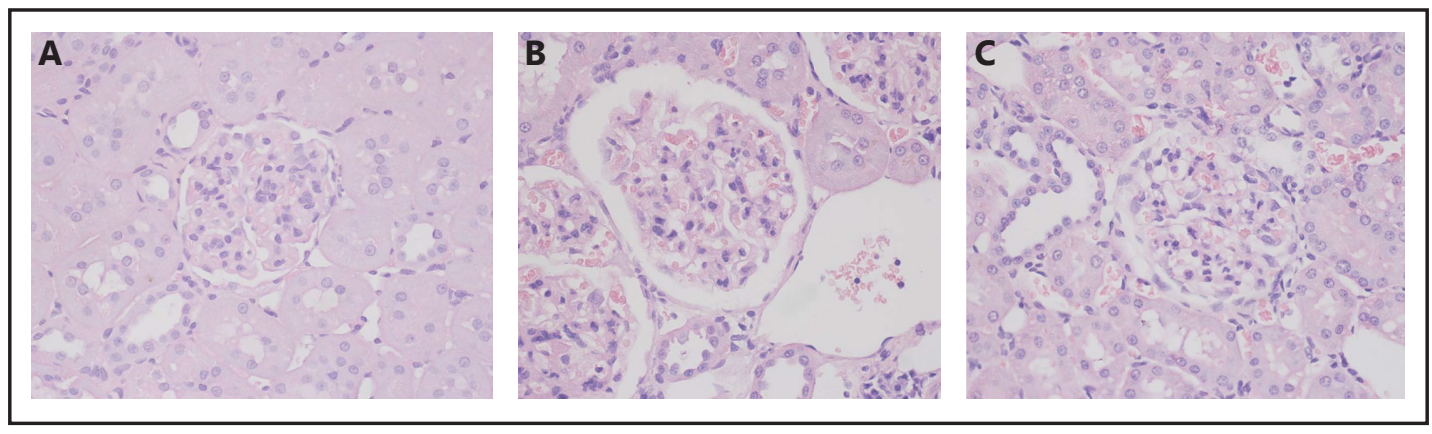

Fig. 4. Hematoxylin-eosin (HE) staining. A. No inflammatory cells were observed in the renal tissue of control rats. B. Infiltration of renal tissue by inflammatory cells was observed in the diabetic group. C. Fewer inflammatory cells were observed in the renal tissue of the irbesartan-treated group.
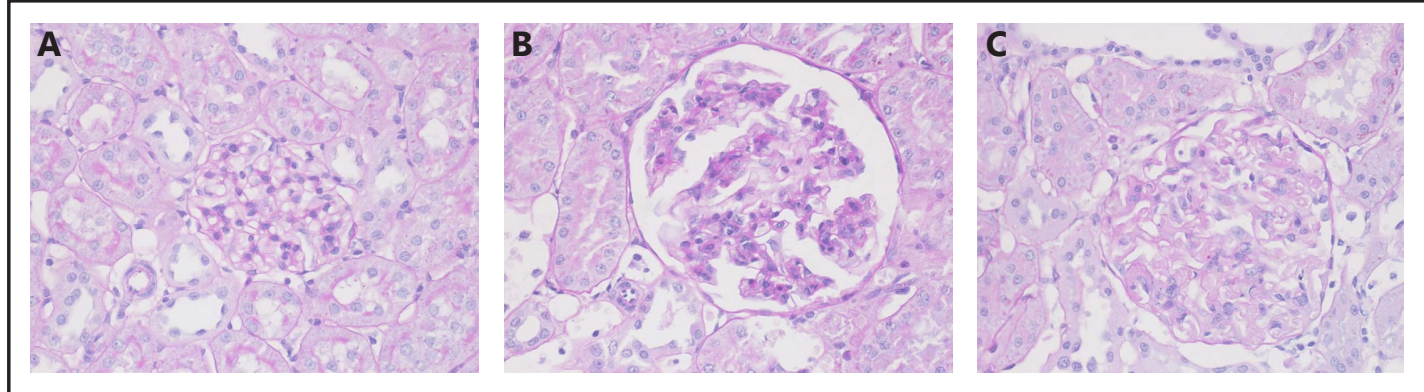

Fig. 5. PAS staining. A. No marked changes were observed in the PAS-stained renal tissue of control rats. B. Thickening of the glomerular basement membranes, increased ECM, and enlargement of the mesangial region were observed in the diabetic group. C. The thickening of the glomerular basement membranes, increased ECM, and enlargement of the mesangial region were reversed in the diabetic + irbesartan group.

\section{Effects of irbesartan on the renal pathological changes associated with T2DM}

As shown in Fig. 4, HE staining revealed infiltration of the renal tissue by inflammatory cells in the diabetic group. Fewer inflammatory cells were observed in the renal tissue of the irbesartan-treated group. Furthermore, PAS staining showed thickening of the glomerular basement membranes, increased ECM, and enlargement of the mesangial region in the diabetic group, which were reversed with irbesartan (Fig. 5).

\section{Discussion}

In this preliminary study, we assessed the changes in chemerin expression in control rats, diabetic rats treated the irbesartan and untreated diabetic rats to understand its possible role in DN and how the activation of intrarenal RAS might influence chemerin expression in the kidneys of diabetic rats. Our results showed that chemerin expression may be inhibited in diabetic rats treated with irbesartan and that irbesartan-induced reduction in RAS components may be the result of an inhibitory effect on their activation, which in turn affects the expression of chemerin in renal tissue.

There is increasing evidence showing that adipokines play a key role in the development of obesity, IR, and T2DM and its chronic complications. The levels of chemerin, an adipokine identified fairly recently, were correlated with body mass index (BMI) and components of the metabolic syndrome in normal and overweight subjects [5, 7-19]. It has also been shown 


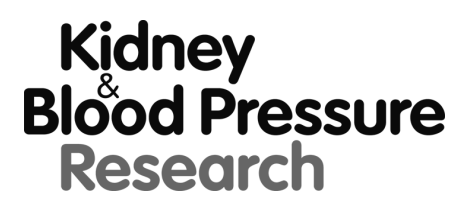

Kidney Blood Press Res 2015;40:467-477

\begin{tabular}{l|l}
\hline DOI: $10.1159 / 000368523$ & (c) 2015 S. Karger AG, Basel
\end{tabular}

Published online: September 22, 2015

www.karger.com/kbr

474

Yu/Zhang/Xu/Hao/Liu/Bai/Mu/Zhang: Irbesartan Effects on Chemerin in Diabetic Rats

that the levels of chemerin in patients with metabolic syndrome are significantly correlated with BG, high density lipoprotein-cholesterol (HDL-C), CHOL, TG, CRP, fasting insulin and the homeostatic model assessment (HOMA) index [18, 20-22], whereas a negative correlation exists with the glomerular filtration rate (GFR) [23]. Studies also indicate that serum chemerin levels are significantly elevated in patients on chronic hemodialysis and are correlated with renal function [7]. The serum chemerin concentration in patients with end-stage renal disease (ESRD) normalizes after kidney transplantation, which provides additional evidence that serum chemerin concentration is related to renal function [8]. It also has been suggested that chemerin is independently associated with markers of IR and renal dysfunction in patients with gestational diabetes mellitus (GDM) as compared to healthy pregnant controls [24]. In addition, chemerin expression in kidney tissue is increased in animal models of T2DM [25]. Serum chemerin is also significantly elevated in type 2 diabetic patients with macroalbuminuria compared with control subjects and diabetic patients with normoalbuminuria and microalbuminuria [26]. Our results show that the expression of chemerin in the kidney of diabetic rats is significantly elevated compared to that in the control group, suggesting that chemerin may potentially play an important role in the pathology of DN.

Numerous studies have suggested that the activation of RAS and an increase in the local production of Ang II play important roles in the progression of DN. RAS blockers reduce proteinuria by acting on intraglomerular pressure, mesangial contractility and proximal tubular solute transport [27]. Moreover, RAS blockers improve the endothelial function, inflammation, IR and oxidative stress [28, 29]. RAS blockers also increase plasma adiponectin levels while decreasing proteinuria in patients with DN [30]. However, few studies have investigated the relationship between RAS and chemerin. Hoppmann et al. [31] indicated that selective mineralocorticoid receptor (MR) stimulation with aldosterone promoted the expression of chemerin. Similarly, John et al. [32] identified that angiotensin-convertingenzyme (ACE) was responsible for C-terminal truncation of chemerin, which was completely inhibited by captopril. Proteolytic processing of the C-terminus of chemerin is essential for receptor binding and physiological activity, and administration of captopril inhibited the ACE-induced C-terminal truncation [32], demonstrating the role of ACE in mediating immune response and in influencing chemerin expression. In our opinion, the present study has demonstrated a similar mechanism, since the evaluation of diabetic rats treated with irbesartan showed decreased expression levels of chemerin and RAS components, which were elevated prior to treatment.

The expression of chemerin and its receptors (chemokine receptor 1, chemokine receptor-like 2, and G protein-coupled receptor-like 1) are shown to be altered in white adipose tissue, skeletal muscle and liver tissue of obese diabetic mice compared to normoglycemic mice [33]. Chemerin regulates adipocyte differentiation and metabolism by binding to and activating the G protein coupled receptor-like 1 (CMKLR-1), and there is evidence that this receptor influences the development of adipose tissue, inflammation and glucose homeostasis, contributing to the metabolic dysfunction seen in obesity and obesity-related diseases, such as diabetes. Although much remains to be learned about the processing of chemerin and its physiological functions, it appears unambiguous that chemerin receptor binding capacity is involved in the mechanism governing the expression of chemerin. Our data show that irbesartan treatment suppressed chemerin and RAS-related proteins in the kidneys of diabetic rats. These findings provide compelling evidence that chemerin expression levels in the kidney of diabetic rats are associated with the RAS-related factors.

\section{Limitations}

The results of this preliminary study are limited in that the mechanisms underlying the effects of irbesartan on chemerin expression in the kidneys of diabetic rats remain unknown, especially with respect to the role of intrarenal RAS activation. Our results suggest that 


\section{Kidney \\ Blood Pressure Research}

irbesartan does not directly affect RAS parameters alone, but is likely mediated as a result of glucose control. Thus, further studies are required to clarify the relationship between the following factors: irbesartan, blood glucose and RAS. Applying immunofluorescence or confocal microscopy may help to provide more definitive results to examine differences in expression levels. Although PCR was used to quantify the mRNA levels of chemerin and angiotensin II receptors, ELISA or a radioactive-based assay would provide more information about their protein levels. Furthermore, understanding the role of chemerin, a potent chemokine in DN, in mediating renal damage and infiltration of macrophages may shed light on the mechanism.

\section{Conclusion}

In conclusion, our findings show that treating diabetic rats with irbesartan reduces the overexpression of chemerin and RAS-related proteins in the kidneys, The results of this preliminary study suggest that irbesartan may have an inhibitory effect on the activation of intrarenal RAS, which may in turn affect the expression of chemerin in the kidneys of diabetic rats and ultimately benefit renal function. Further studies are necessary to confirm the results of the present study and to understand the underlying molecular mechanisms responsible for altering the chemerin-RAS pathway in DN.

\section{Disclosure Statement}

The authors of this manuscript state that they do not have any conflict of interests and nothing to disclose.

\section{Acknowledgements}

This study was sponsored by the National Natural Science Foundation of China (81202189) and the Education Department of Heilongjiang province (12531233).

\section{References}

1 Goralski KB, McCarthy TC, Hanniman EA, Zabel BA, Butcher EC, Parlee SD, Muruganandan S, Sinal CJ: Chemerin, a novel adipokine that regulates adipogenesis and adipocyte metabolism. J Biol Chem 2007;282:28175-28188.

2 Wittamer V, Bondue B, Guillabert A, Vassart G, Parmentier M, Communi D: Neutrophil-mediated maturation of chemerin: a link between innate and adaptive immunity. J Immunol 2005;175:487-493.

3 Yu S, Zhang Y, Li MZ, Xu H, Wang Q Song J, Lin P, Zhang L, Liu Q, Huang QX, Wang K, Hou WK: Chemerin and apelin are positively correlated with inflammation in obese type 2 diabetic patients. Chin Med J (Engl) 2012;125:3440-3444.

4 Lehrke M, Becker A, Greif M, Stark R, Laubender RP, von Ziegler F, Lebherz C, Tittus J, Reiser M, Becker C, Göke B, Leber AW, Parhofer KG, Broedl UC: Chemerin is associated with markers of inflammation and components of the metabolic syndrome but does not predict coronary atherosclerosis. Eur J Endocrinol 161: 339-344, 2009.

5 Weigert J, Neumeier M, Wanninger J, Filarsky M, Bauer S, Wiest R, Farkas S, Scherer MN, Schäffler A, Aslanidis C, Schölmerich J, Buechler C: Systemic chemerin is related to inflammation rather than obesity in type 2 diabetes. Clin Endocrinol (Oxf) 2010;72:342-348. 


\section{Kidney \\ Blood Pressure Research}

6 Landgraf K, Friebe D, Ullrich T, Kratzsch J, Dittrich K, Herberth G, Adams V, Kiess W, Erbs S, Körner A: Chemerin as a mediator between obesity and vascular inflammation in children. J Clin Endocrinol Metab 2012;97:E556-564.

7 Pfau D, Bachmann A, Lossner U, Kratzsch J, Bluher M, Stumvoll M, Fasshauer M: Serum levels of the adipokine chemerin in relation to renal function. Diabetes Care 2010;33:171-173.

8 Rutkowski P, Sledzinski T, Zielinska H, Lizakowski S, Goyke E, Szrok-Wojtkiewicz S, Swierczynski J, Rutkowski B: Decrease of serum chemerin concentration in patients with end stage renal disease after successful kidney transplantation. Regul Pept 2012;173:55-59.

9 Wagman AS and Nuss JM: Current therapies and emerging targets for the treatment of diabetes. Curr Pharm Des 2001;7:417-450.

10 Pichler RH, de Boer IH: Dual renin-angiotensin-aldosterone system blockade for diabetic kidney disease. Curr Diab Rep 2010;10:297-305.

11 Henriksen EJ, Jacob S, Kinnick TR, Teachey MK, Krekler M: Selective angiotensin II receptor antagonism reduces insulin resistance in obese Zucker rats. Hypertension 2001;38:884-890.

12 Marrero MB, Fulton D, Stepp D, Stern DM: Angiotensin II-induced insulin resistance and protein tyrosine phosphatases. Arterioscler Thromb Vasc Biol 2004;24:2009-2013.

13 Wei Y, Sowers JR, Nistala R, Gong H, Uptergrove GM, Clark SE, Morris EM, Szary N, Manrique C, Stump CS: Angiotensin II-induced NADPH oxidase activation impairs insulin signaling in skeletal muscle cells. J Biol Chem 2006;281:35137-35146.

14 Chatzikyrkou C, Menne J, Haller H: How to achieve renal protection in the light of ONTARGET? J Hypertens 2009;27:S15-17.

15 Parving HH, Lehnert H, Brochner-Mortensen J, Gomis R, Andersen S, Arner P, Irbesartan in Patients with Type 2 Diabetes and Microalbuminuria Study Group: The effect of irbesartan on the development of diabetic nephropathy in patients with type 2 diabetes. N Engl J Med 2001;345:870-878.

16 Reed MJ, Meszaros K, Entes LJ, Claypool MD, Pinkett JG., Gadbois TM, Reaven GM: A new rat model of type 2 diabetes: the fat-fed, streptozotocin-treated rat. Metabolism 2000;49:1390-1394.

17 Bozaoglu K, Bolton K, McMillan J, Zimmet P, Jowett J, Collier G, Walder K, Segal D: Chemerin is a novel adipokine associated with obesity and metabolic syndrome. Endocrinology 2007;148:4687-4694.

18 Bozaoglu K, Segal D, Shields KA, Cummings N, Curran JE, Comuzzie AG, Mahaney MC, Rainwater DL, VandeBerg JL, MacCluer JW, Collier G, Blangero J,Walder K, Jowett JB: Chemerin is associated with metabolic syndrome phenotypes in a Mexican-American population. J Clin Endocrinol Metab 2009;94:3085-3088.

19 Bremer AA, Jialal I: Adipose tissue dysfunction in nascent metabolic syndrome. J Obes 2013;2013:393192.

20 Stefanov T, Bluher M, Vekova A, Bonova I, Tzvetkov S, Kurktschiev D, Temelkova-Kurktschiev T: Circulating chemerin decreases in response to a combined strength and endurance training. Endocrine 2013;45:382391.

21 Kim SH, Lee SH, Ahn KY, Lee DH, Suh YJ, Cho SG, Choi YJ, Lee DH, Lee SY, Hong SB, Kim YS, Jeon JY, Nam M: Effect of lifestyle modification on serum chemerin concentration and its association with insulin sensitivity in overweight and obese adults with type 2 diabetes. Clin Endocrinol (Oxf) 2013;80:825-833.

22 Lee MK, Chu SH, Lee DC, An KY, Park JH, Kim DI, Kim J, Hong S, Im JA, Lee JW, Jeon JY: The association between chemerin and homeostasis assessment of insulin resistance at baseline and after weight reduction via lifestyle modifications in young obese adults. Clin Chim Acta 2013;421:109-115.

23 Yamamoto T, Qureshi AR, Anderstam B, Heimburger O, Barany P, Lindholm B, Stenvinkel P, Axelsson J: Clinical importance of an elevated circulating chemerin level in incident dialysis patients. Nephrol Dial Transplant 2010;25:4017-4023.

24 Pfau D, Stepan H, Kratzsch J, Verlohren M, Verlohren, HJ, Drynda K, Lössner U, Blüher M, Stumvoll M, Fasshauer M: Circulating levels of the adipokine chemerin in gestational diabetes mellitus. Horm Res Paediatr 2010;74:56-61.

$25 \mathrm{Hu}$ W, Yu Q, Zhang J, Liu D: Rosiglitazone ameliorates diabetic nephropathy by reducing the expression of Chemerin and ChemR23 in the kidney of streptozotocin-induced diabetic rats. Inflammation 2012;35:1287-1293. 


\section{Kidney \\ Bloód Pressure Research}

\section{Kidney Blood Press Res 2015;40:467-477}

26 Hu W, Feng P: Elevated serum chemerin concentrations are associated with renal dysfunction in type 2 diabetic patients. Diabetes Res Clin Pract 2011;91:159-163.

27 Ruggenenti P, Perna A, Benini, R, Bertani T, Zoccali C, Maggiore Q Salvadori M, Remuzzi G: In chronic nephropathies prolonged ACE inhibition can induce remission: dynamics of time-dependent changes in GFR. Investigators of the GISEN Group. Gruppo Italiano Studi Epidemiologici in Nefrologia. J Am Soc Nephrol 1999;10:997-1006.

28 Miyazaki Y, Murakami H, Hirata A, Fukuoka M, Masuda A, Ura N, Shimamoto K: Effects of the angiotensin converting enzyme inhibitor temocapril on insulin sensitivity and its effects on renal sodium handling and the pressor system in essential hypertensive patients. Am J Hypertens 1998;11:962-970.

29 Barra S, Vitagliano A, Cuomo V, Vitagliano G, Gaeta G: Vascular and metabolic effects of angiotensin II receptor blockers. Expert Opin Pharmacother 2009;10:173-189.

30 Yenicesu M, Yilmaz MI, Caglar K, Sonmez A, Eyileten T, Acikel C, Kilic S, Bingol N, Bingol S, Vural A: Blockade of the renin-angiotensin system increases plasma adiponectin levels in type-2 diabetic patients with proteinuria. Nephron Clin Pract 2005;99:c115-121.

31 Hoppmann J, Perwitz N, Meier B, Fasshauer M, Hadaschik D, Lehnert H, Klein J: The balance between gluco- and mineralo-corticoid action critically determines inflammatory adipocyte responses. J Endocrinol 2010;204:153-164.

32 John H, Hierer J, Haas O, Forssmann WG: Quantification of angiotensin-converting-enzyme-mediated degradation of human chemerin 145-154 in plasma by matrix-assisted laser desorption/ionization- timeof-flight mass spectrometry. Anal Biochem 2007;362:117-125.

33 Ernst MC, Haidl ID, Zúñiga LA, Dranse HJ, Rourke JL, Zabel BA, Butcher EC, Sinal CJ: Disruption of the chemoking-like receptor-1 gene is associated with reduced adiposity and glucose intolerance. Endocrinology 2012;153:672-682. 